\title{
Neurobiological features common to memory modulation by many treatments
}

\author{
PAUL E. GOLD \\ University of Virginia, Charlottesville, Virginia
}

\begin{abstract}
Evidence reviewed here suggests that many treatments that retroactively enhance or impair memory in rats and mice may act by releasing epinephrine from the adrenal medulla: (1) When administered shortly after training, epinephrine injections modulate memory storage processes; (2) plasma epinephrine levels assessed shortly after training predict later performance of learned responses in several situations; and furthermore, (3) peripherally administered adrenergic antagonists block the effects on memory of epinephrine and of many other treatments that enhance and impair memory. In addition, the rapid forgetting exhibited by juvenile and aged rodents can be retarded (i.e., memory is improved) by posttraining epinephrine injections, suggesting that age-related memory deficits may reflect inadequate functions of those neuroendocrine systems responsible, in part, for regulating memory storage. These results, together with the additional finding that epinephrine enhances the establishment of a neurophysiological analogue of memory, long-term potentiation, suggest that the hormone regulates neurobiological processes responsible for memory formation.
\end{abstract}

Evidence accumulated over the past 25 years indicates that, if administered soon after a training experience, a variety of treatments can retroactively modify memorystorage processing (Gold \& Zornetzer, 1983; McGaugh, 1966; McGaugh \& Herz, 1972). Amnestic agents used in the past have included electroconvulsive shock, localized electrical stimulation of the brain, and drugs that interfere with protein synthesis, neurotransmitter synthesis, or neurotransmitter function. When considered with the finding that retrograde amnesia can be observed after training in a wide range of behavioral tasks and in a large number of species, two features are clear. First, if a treatment produces amnesia in one task or in one species, that treatment is likely to do so in other tasks and other species. Second, although the specific time course may vary widely under different conditions, the treatments produce more severe memory disruption when administered soon after training than they do when administered at long delays after training. Similarly, many studies provide evidence that some treatments, including administration of such stimulant drugs as amphetamine and low doses of pentylenetetrazol, can enhance the storage of recent information. Here again, the treatments have the largest effects on memory when administered at short intervals after training. The generality of these findings, in terms of task, species, and time-dependency, suggests some biological commonalities in the mechanisms by which most treatments modulate memory-storage processes under a broad spectrum of specific experimental conditions. A

Presented at the Seventh Harvard Symposium on Quantitative Analyses of Behavior: Biological Determinants, Harvard University, June 8-9, 1984. Much of the research reported in this paper was supported by Grants MH 31141 and AG 01641 and by an award from the James McKeen Cattell Foundation. Paul E. Gold's mailing address is Department of Psychology, Gilmer Hall, University of Virginia, Charlottesville, VA 22903. major goal of this paper is to define the features common to memory modulation at a neurobiological level.

The fact that memory storage is particularly susceptible to retroactive treatments for only a short time after an experience suggests that there also may be endogenous systems that retroactively regulate the storage of new information (Gold \& McGaugh, 1975, 1978). The endogenous systems may include arousal level or hormonal responses to an experience. Such a view would seem to have a great deal of intuitive appeal, which perhaps explains the frequent storage of "trivial" information that accompanies times of high arousal. For example, many people remember where they were on Pearl Harbor Day, on the day of President Kennedy's assassination, or on the days their children were born. These memories contrast sharply with recollections of memories of events occurring on days surrounding such momentous events. The detailed recollection of minor activities at the time of very joyous or very sad occasions suggests that our brains are physiologically prepared to store new information at those times. More commonly, one tends to remember important events more readily than unimportant events. Perhaps the rewards and punishments that accompany significant experiences regulate the storage of information by establishing a physiological state optimal for memory storage. Recently, work in my laboratory and others has focused on the possibility that hormonal responses to an experience define such a physiological state and thereby regulate memory storage (see Gold \& Zornetzer, 1983; McGaugh, 1983).

\section{PERIPHERAL EPINEPHRINE AND MEMORY STORAGE}

Because of the temporal constraints on the time after training during which a treatment may modulate memory 


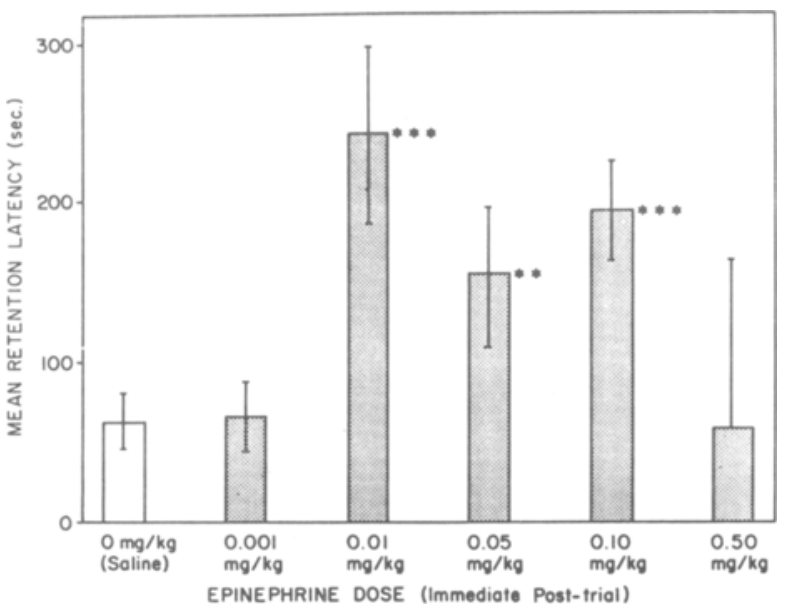

Figure 1. Mean latencies to lick (and standard errors) for animals that received saline or epinephrine immediately after training. Within the dose range $0.01-0.1 \mathrm{mg} / \mathrm{kg}$, retention performance was significantly facilitated. ${ }^{* * *} p<.001 ;{ }^{* *} p<.01$. (From "Facilitation of Time-Dependent Memory Processes with Posttrial Epinephrine Injections" by P. E. Gold \& R. B. van Buskirk, 1975, Behavioral Biology, 13, pp. 145-153. Copyright 1975 by Academic Press. Reprinted by permission.)

storage, and because of the need to have tight control over the time at which training-related hormonal responses were measured, most of the behavioral studies that will be described here employed a one-trial inhibitory (passive) avoidance task. Many of the findings, however, have been replicated in principle using other tasks as well. In an inhibitory avoidance task, an animal receives a single brief footshock upon entering a dark compartment. Not surprisingly, the animal's avoidance behavior (i.e., the latency to enter the dark chamber) increases as the intensity and/or duration of the footshock are increased. More remarkably, however, if the animal is given a mild footshock followed immediately by a peripheral injection of any of several hormones, the avoidance behavior is improved on a test trial administered $24 \mathrm{~h}$ after training. One interpretation of such findings is that the hormonal injection enhances memory by experimentally mimicking those hormonal consequences that would follow a more intense training experience.

Perhaps the most extensive documentation of such results comes from experiments in which the hormone used was epinephrine. Some early findings are illustrated in Figure 1. In this study (Gold \& van Buskirk, 1975), animals were pretrained to drink from a water spout at the end of a long alley. After several days of pretraining, the animals had very low latencies to approach and to drink from the water spout. On the avoidance trial, each animal received a brief mild footshock while drinking, and then received an injection of saline or one of several epinephrine doses. Note that the animals that received saline had latencies to drink of about $50 \mathrm{sec}$. The animals that received epinephrine injections had significantly better retention performance at the intermediate doses tested.
At higher doses, epinephrine did not affect memory; in other studies, such doses were found to produce amnesia (e.g., Gold \& van Buskirk, 1976, 1978a, 1978b). The inverted-U dose-response curve appears to be characteristic of nearly all treatments that can retroactively affect memory (see Gold, 1984), which is another feature common to memory-modulating agents. In addition, epinephrine injections were found to be less effective in enhancing memory if delayed by $\mathbf{3 0}$ min or longer after training (Figure 2).

Although the effects on memory of such pharmacological manipulations are consistent with the view that endogenous posttraining hormonal responses are important in regulating the storage of new information, it must also be demonstrated that such responses indeed occur after training and that the doses injected result in plasma epinephrine levels that are physiologically significant to the animal. To address these questions, animals were prepared with chronic tail artery catheters (Chiueh \& Kopin, 1978). This procedure allows the investigator the opportunity to take plasma samples from behaving rats and to assay the epinephrine content in those samples. The results of one such study are shown in Figure 3 . In this experiment (McCarty \& Gold, 1981), rats were trained in an inhibitory avoidance task, as before, with either a mild or an intense footshock. Note that plasma epinephrine levels were quite sensitive to behavioral manipulations. Merely placing the animal in the training apparatus was sufficient to significantly elevate these levels. The mild footshock did not raise these levels further. However, the intense training footshock resulted in a 10- to 15-fold increase in plasma epinephrine levels above basal values. In another study (Gold \& McCarty, 1981), it was found

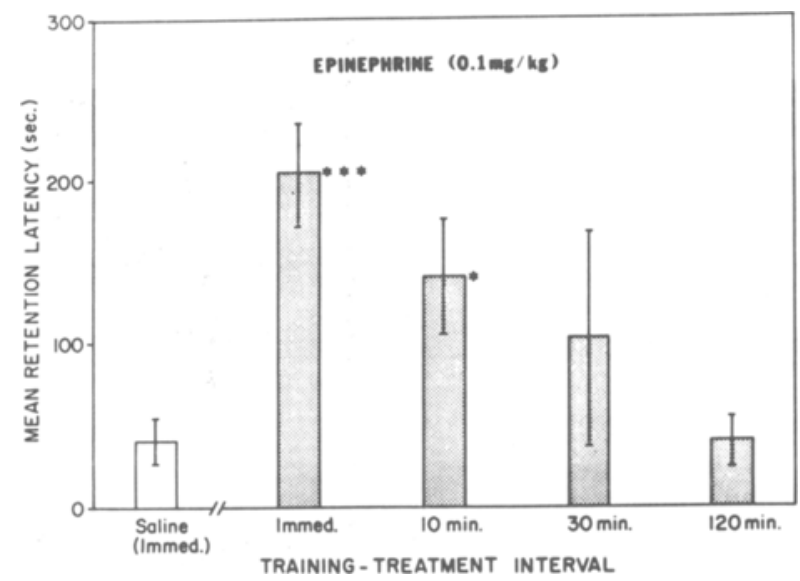

Figure 2. Mean latencies to lick (and standard errors) for animals that received saline immediately after training or epinephrine $(0.1 \mathrm{mg} / \mathrm{kg})$ at various delays after training. Note that the effectiveness of the drug in facilitating retention varied inversely with the training-treatment interval. ${ }^{* *} p<.001 ;{ }^{*} p<.05$. (From "Facilitation of Time-Dependent Memory Processes with Posttrial Epinephrine Injections" by P. E. Gold \& R. B. van Buskirk, 1975, Behavioral Biology, 13, pp. 145-153. Copyright 1975 by Academic Press. Reprinted by permission.) 
that epinephrine injections at doses that enhanced memory resulted in plasma levels that were comparable to the peak levels seen after the strong footshock. Furthermore, amnestic doses of epinephrine, as well as supraseizure electrical stimulation of frontal cortex, resulted in supraphysiological plasma epinephrine levels.

Results of studies of age-related changes in learning and memory suggest that epinephrine may also be an important contributor to the poor memory frequently observed in juvenile and aged rats (Gold, Murphy, \& Cooley, 1982). Fourteen-day-old rats that received one-trial inhibitory avoidance training exhibited poor retention performance when tested 1 or $24 \mathrm{~h}$ after training. Sixteenday-old rats had good retention $1 \mathrm{~h}$ after training, but poor retention after a 24-h interval. Older animals (up to 90 days) had good retention performance at both trainingtest intervals. This ontogenetic pattern of development of 24-h retention performance is seen in a variety of conditions. One interpretation is that the memory processes necessary to store new information mature at about 16 days. Alternatively, it may be that the memory processes are sufficiently mature to store the information, but the hormonal modulators are not yet responsive to the training conditions. To test this possibility, posttraining injections of epinephrine, norepinephrine, or ACTH were administered to 16-day-old rats, and the animals were tested for retention performance $24 \mathrm{~h}$ later. As indicated in Figure 4, the peripheral catecholamine injections, but not

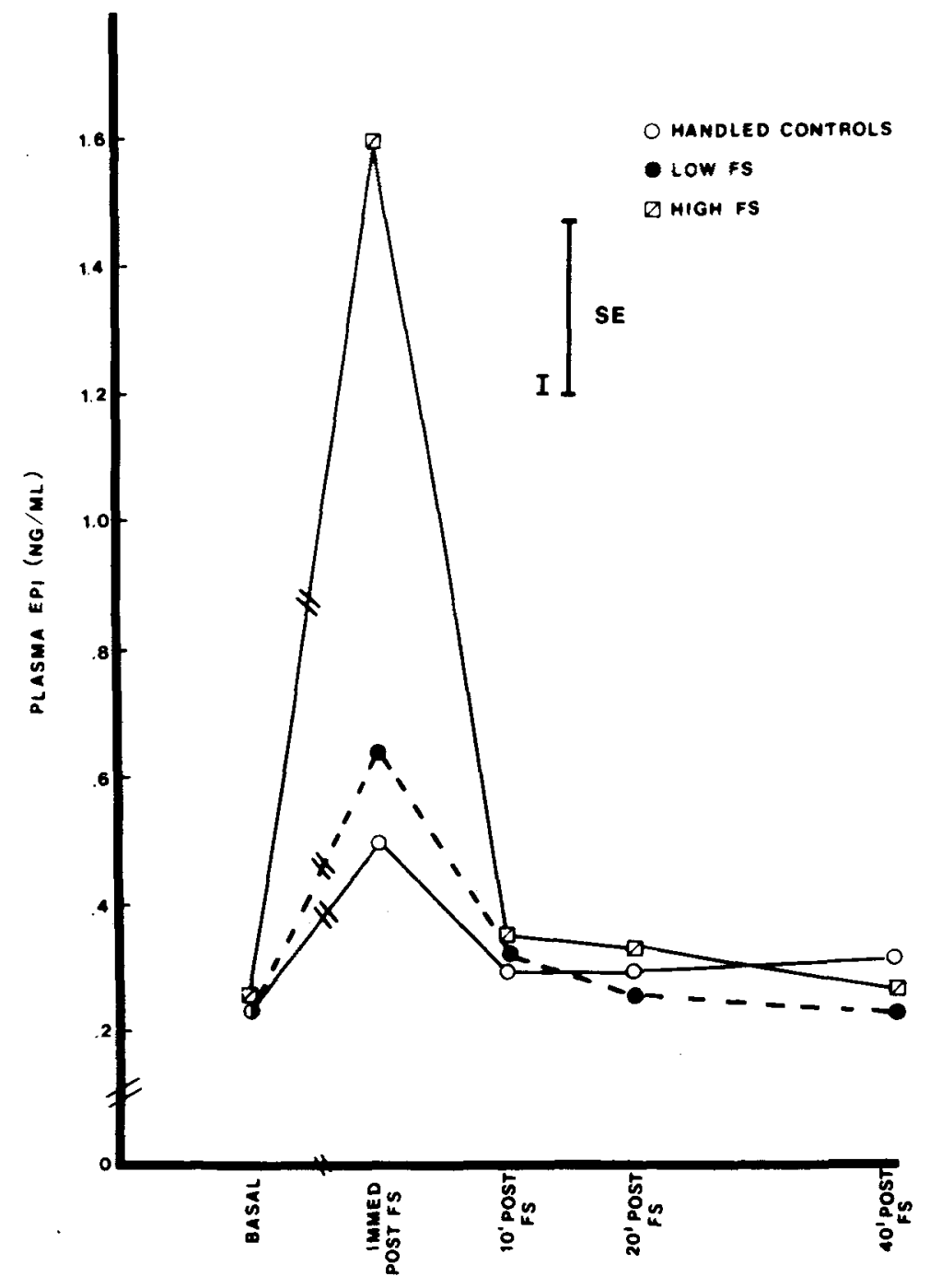

Figure 3. Plasma levels of epinephrine (EPI, ng/ml) under basal conditions and after handling or exposure to a training footshock. Values are means for 6-7 animals per group, and the range of standard errors (SEs) is indicated. (From "Plasma Catecholamines: Effects of Footshock Level and Hormonal Modulators of Memory Storage" by R. McCarty \& P. E. Gold, 1981, Hormones \& Behavior, 15, pp. 168182. Copyright 1981 by Academic Press. Reprinted by permission.) 
ACTH, enhanced retention performance at the test trial $24 \mathrm{~h}$ after training. Even a high training footshock failed to result in good retention on the 24-h test trial. These findings suggest that the neurobiological mechanisms essential for memory storage may develop before the development of the neuroendocrine responses that modulate memory storage.

Recent findings of studies of aged (2-year-old) rats and mice indicate that these animals exhibit very rapid forgetting (Bartus, Dean, Beer, \& Lippa, 1981; Gold, McGaugh, Hankins, Rose, \& Vasquez, 1981; Zornetzer, Thompson, \& Rogers, 1982) and, in addition, exhibit diminished epinephrine release in response to moderate footshock (McCarty, 1981). However, as shown in Figure 5, retention performance in these animals can be significantly enhanced when measured 1 to 7 days later by a single posttraining epinephrine injection (Sternberg, Martinez, Gold, \& McGaugh, 1985). Thus, agerelated changes in peripheral adrenergic responses to training may contribute to the memory deficits which accompany aging.

The research described thus far illustrates some of the generality of the effects on memory of peripheral epinephrine. The inverted- $U$ relationship between epinephrine and memory can be observed, with direct injections of different epinephrine doses, by measuring the plasma values for epinephrine levels after administering memory-modulating treatments and by examining these effects against developmental and aging backgrounds.

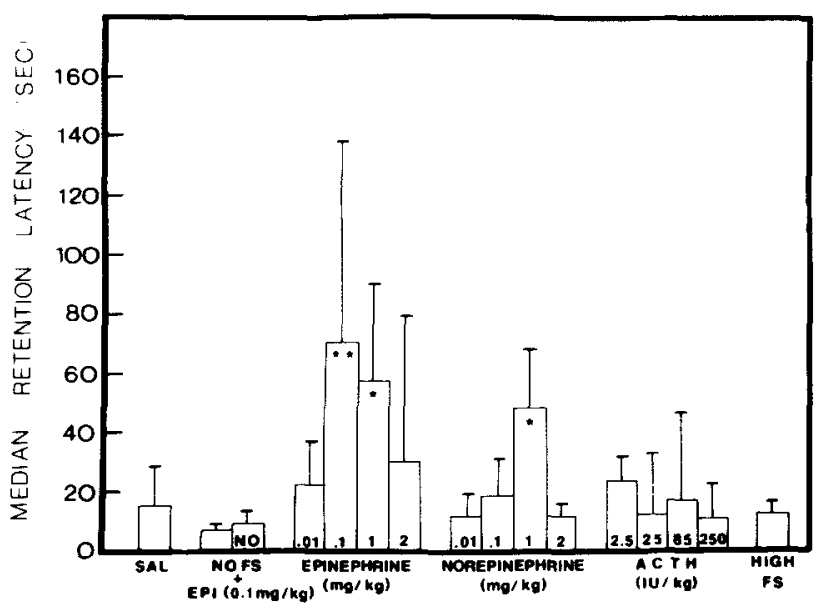

Figure 4. Effects of immediate posttraining injections of epinephrine, norepinephrine, or ACTH on 24-h retention performance of 16-day-old rats. Intermediate doses of the catecholamines enhanced 24-h retention performance. ACTH was inefiective at all doses tested. Also, animals trained with high footshock levels failed to show better $24 \mathrm{~h}$ retention performance than did those animals trained with lower footshock. (From "Neuroendocrine Modulation of Memory During Development" by P. E. Gold, J. M. Murphy, \& S. Cooley, 1982, Behavioral \& Neural Biology, 35, pp. $277-293$. Copyright 1982 by Academic Press. Reprinted by permission.)
Epinephrine Facilition-Old Rats

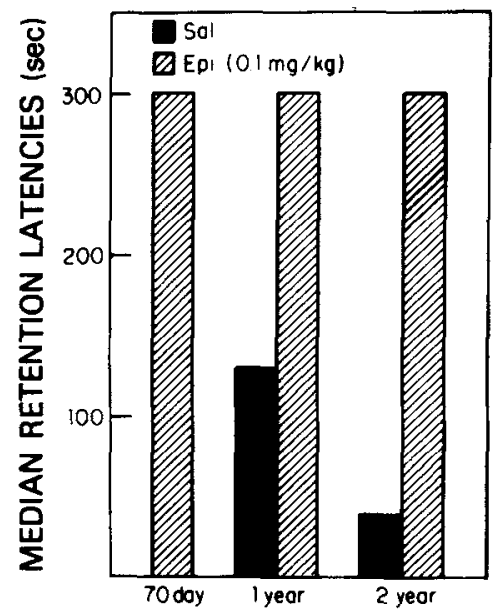

$(200 \mu \mathrm{A}, 0.4 \mathrm{sec}$ fs, I week retention test)

Figure 5. Retention performance of rats in a one-trial inhibitory avoidance task. Retention is expressed as latency to reenter the shock compartment 1 week following training. There occurred a significant decrease in retention performance in old rats. A posttraining injection of epinephrine enhanced retention performance of both 1- and 2-year-old rats. (From “Age-Related Memory Deficits in Aged Rats and Mice: Enhancement with Peripheral Injections of Epinephrine" by D. B. Stemberg, J. Martinez, P. E. Gold, \& J. L. McGaugh, 1985, Behavioral \& Neural Biology, 44, pp. 213-220. Copyright 1985 by Academic Press. Reprinted by permission.)

\section{ATTENUATION OF MEMORY MODULATION WITH ADRENERGIC ANTAGONISTS}

The findings described above indicate that a single hormone, epinephrine, mirrors the major effects on memory that had been observed in memory-consolidation research. Is it possible that other amnestic and memory-enhancing treatments might act on memory via modifications of peripheral epinephrine? There are two major ways to address this question. The first is to assess the adrenal medullary responses to a variety of agents that modulate memory. As mentioned above, in one experiment of this sort, plasma catecholamine content was examined at various times after training and treatment with supraseizure frontal cortex stimulation (Gold \& McCarty, 1981). The results indicate that the amnestic treatment does, in fact, result in supraphysiological plasma epinephrine levels. Such results, then, are consistent with the hypothesis that frontal cortex stimulation may act on memory by releasing excessive amounts of epinephrine. On the other hand, injections of ACTH or an ACTH analogue-both drugs that enhance memory-do not result in increased plasma epinephrine levels. Therefore, ACTH appears to act on memory via other mechanisms.

A second way to address the issue of the possible involvement of epinephrine in mediating the effects of many treatments on memory is to use adrenergic receptor an- 
tagonists in conjunction with the memory modulators to attempt to attenuate the memory facilitation and amnesia. In the first study of this type (Gold \& Sternberg, 1978 ), rats or mice received a pretraining injection of phenoxybenzamine, an $\alpha$-adrenergic antagonist. The animals were trained $30 \mathrm{~min}$ later, and received one of several amnestic treatments-frontal cortex stimulation, subseizure electrical stimulation of the amygdala, pentylenetetrazol (at a convulsant dose), diethyldithiocarbamate (a norepinephrine synthesis inhibitor), or cycloheximide (a protein synthesis inhibitor). These treatments were thought to act on memory through very different mechanisms (e.g., by producing brain seizures, or by blocking norepinephrine or protein synthesis). Despite these diverse modes of putative action, the amnestic effect of each of the treatments was blocked by the adrenergic antagonist. Any of several other antagonists are also effective in attenuating memory modulation (Sternberg \& Gold, 1980, 1981). Thus, another feature most memorymodulating treatments have in common is that their effects on memory are blocked by peripheral injections of adrenergic antagonists. A further characteristic of memory-modulating agents is that most seem capable of both enhancing and impairing memory. The important variables are the treatment and training parameters. For instance, if animals are trained with low or high footshock levels, the same treatment will enhance memory for lowfootshock training and impair memory for high-footshock training. A recent study (Sternberg, McGaugh, \& Gold, 1983) exemplifies these results. This experiment repeated the previous findings that frontal-cortex stimulation, at an intensity that resulted in brain seizures in all animals, was an effective amnestic treatment when administered after high-footshock training. Furthermore, the memory impairment was attenuated in animals pretreated with a $\beta$-adrenergic antagonist, propranolol. Remarkably, the same intensity supraseizure frontal-cortex stimulation enhanced memory when administered after low-footshock training; this effect on memory also was blocked by propranolol pretreatment. Therefore, an additional characteristic of memory modulation observed with diverse treatments is that most treatments can either enhance or impair memory, depending on the level of training-related stress (e.g., footshock intensity). When this observation is combined with the classic characteristic that defines memory-modulation actions (i.e., retrograde timedependent effects on memory), one reasonable hypothesis might be that these treatments, with diverse putative neurobiological actions, act on memory storage by common mechanisms. Furthermore, the hypothesis that many effects on memory are mediated by peripheral adrenergic mechanisms accounts for a substantial amount of the current data.

\section{ADRENERGIC MODULATION OF LONG-TERM POTENTIATION}

In recent years, the list of long-lasting changes in the central nervous system after brain damage, stress, or ex- perience has been growing rapidly (see Gold, 1984). One neuronal change that has received considerable attention in memory research is long-term potentiation (LTP). This phenomenon, most often examined in the hippocampal formation, is characterized by a long-lasting change in a monosynaptic-evoked response after application of a high-frequency stimulation train to the afferent pathway. Because the change in the evoked response is produced rapidly, often within seconds of the high-frequency train, and because the changes in neuronal function are long lasting (evident in some cases months after training), LTP may be a useful neurobiological analogue of memory (see Goddard, 1980). In a set of recent experiments (Delanoy, Gold, \& Tucci, 1983; Gold, Delanoy, \& Merrin, 1984), the possibility was examined that peripheral catecholamines may be able to regulate the establishment of LTP. Under physiological control in anesthetized animals, stimulating electrodes were placed in the perforant path, and the evoked response was assessed from a recording electrode located in the granule cell layer of the dentate gyrus. After a baseline-evoked response was established, each anesthetized animal received an injection of saline, epinephrine, or amphetamine. These injections did not themselves alter the characteristics of the evoked response. Next, high-frequency stimulation trains were applied to the perforant path, and the evoked response was monitored for up to $2 \mathrm{~h}$ thereafter. The results, shown in Figure 6, were collected 20 min after the high-frequency stimulation trains had been administered. Note that both epinephrine and amphetamine enhanced the development of LTP, as assessed here by the growth of the population spike. The enhancement of LTP was stable over time, occurred at doses compatible with those effective in behavioral studies, and exhibited an inverted-U doseresponse curve. These results therefore suggest that LTP

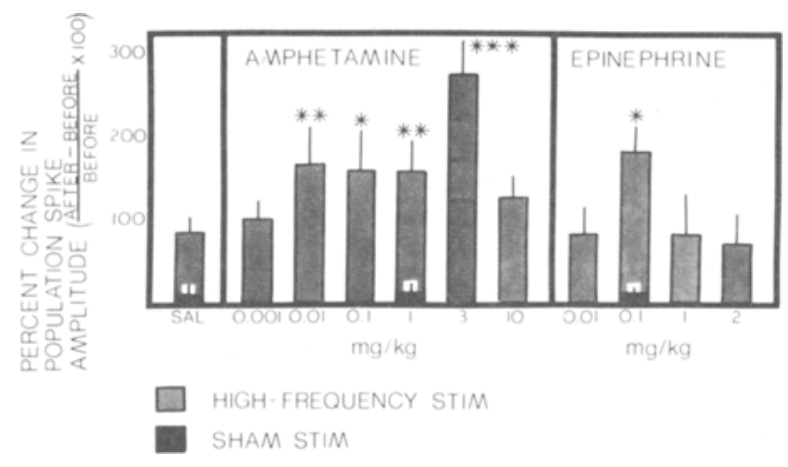

Figure 6. Percent changes (means $\pm S E M$ ) in population spike amplitude 20 min after high-frequency stimulation. A peripheral injection of either amphetamine or epinephrine enhanced the degree of long-term potentiation in an inverted-U dose-response manner. The small internal black bars (saline, $1.0 \mathrm{mg} / \mathrm{kg}$ amphetamine, $0.1 \mathrm{mg} / \mathrm{kg}$ epinephrine) illustrate the stability of the evoked response in drug-tested animals that did not receive a high-frequency stimulation train (vs. saline group: ${ }^{*} p<.05 ;{ }^{* *} p<.01$; ${ }^{* * *} p<.001$ two-tailed $t$ tests). (From "Modulation of Long-Term Potentiation by Peripherally Administered Amphetamine and Epinephrine" by P. E. Gold, R. Delanoy, \& J. Merrin, 1984, Brain Research, 305, pp. 103-107. Copyright 1984 by Elsevier Science Publishers. Reprinted by permission.) 
may involve neurobiological mechanisms that are employed during memory storage and, conversely, that peripheral catecholamines may act on memory by regulating some forms of neuronal plasticity.

\section{CONCLUSIONS}

In this paper, a considerable amount of evidence has been marshalled in support of the view that peripheral epinephrine, derived from the adrenal medulla, is a potent endogenous modulator of memory storage. The possible involvement of this hormone in memory storage is supported by studies of injections of the hormone after training, by correlations between plasma epinephrine levels and memory storage, by studies of age-related changes in memory and in peripheral catecholamine systems, and by the effects of adrenergic antagonists on memory modulation. Furthermore, findings from early studies suggest that epinephrine injections can modulate at least one neurophysiological analogue of memory, LTP; these findings are consistent with the view that the catecholamine may act by regulating neuronal capacity for change. Even with this level of support for the idea that epinephrine is involved in an important way in memory modulation, the reader should be aware that there is no claim for exclusivity of epinephrine in memory modulation. Such a position would be little more than a contemporary pharmacological phrenology (Zornetzer, 1978). There simply is not a comparable level of information available about other hormones and neurotransmitters. When this information is collected, it may well be that other neuromodulators both share actions and have unique actions on memory storage.

Perhaps the largest question still unanswered about epinephrine is how it works on the brain mechanisms responsible for storing new information. The hormone apparently does not enter the brain in large amounts (Axelrod, Weil-Malherbe, \& Tomchick, 1959). Nonetheless, epinephrine has reliable and extensive effects on cognitive function, as described here, as well as on electrographic arousal (Baust, Niemczyk, \& Vieth, 1963) and on the development of amygdaloid-kindled seizures (Welsh \& Gold, 1984). Some possibilities include cardiovascular effects that modify brain blood flow (Berntman, Dahlgren, \& Siesjo, 1978; Dahlgren, Rosen, Sakabe, \& Siesjo, 1980), effects mediated by epinephrine-induced release of brain norepinephrine (Gold \& van Buskirk, 1978a, 1978b), and classic physiological effects of epinephrine, such as providing glucose for increased metabolism (Gold, 1984). As the major mechanisms by which epinephrine acts on memory are identified, the physiological processes that comprise the neural bases of the storage of new information may well become more clear.

\section{REFERENCES}

AXelrod, J., Weil-Malherbe, H., Tomchick, R. (1959). The physiological disposition of $3 \mathrm{H}$-epinephrine and its metabolite metanephrine. Joumal of Pharmacology \& Experimental Therapeu tics, 127, 251-256

Bartus, R. T., DeAN, R. L., III, BeER, B., LiPPA, A. S. (1981) Profound effects of combining choline and piracetam on memory en hancement and cholinergic function in aged rats. Neurobiology of $\mathrm{Ag}$ ing, 2, 105-111.

Baust, W., Niemczyk, H., \& Vieth, K. (1963). The action of blood pressure on the ascending reticular activating system with special reference to adrenalin-induced EEG arousal. Electroencephalography \& Clinical Neurophysiology, 15, 63-72.

Berntman, L., DahlgRen, N., Siesjo, B. K. (1978). Influence of intravenously administered catecholamines on cerebral oxygen consumption and blood flow in the rat. Acta Physiologica Scandanavia. 104, 101-108.

ChIUEh, C. C., KopIN, I. J. (1978). Hyperresponsivity of spontaneously hypertensive rats to indirect measurement of blood pressure. American Journal of Physiology, 234, H690-H695.

Dahlgren, N., Rosen, I., Sakabe, T., \& Siesjo, B. K. (1980). Cerebral functional, metabolic and circulatory effects of intravenous infusion of adrenaline in the rat. Brain Research, 184, 143-152.

Delanoy, R. L., Gold, P. E., \& Tucci, D. L. (1983). Amphetamine effects on long term potentiation of dentate granule cells. Pharmacology Biochemistry \& Behavior, 18, 137-139.

GoDDARD, G. V. (1980). Component properties of the memory machine Hebb revisited. In P. W. Jusczyk \& R. M. Klein (Eds.), The nature of thought: Essays in honor of D. O. Hebb (pp. 231-247). Hillsdale, NJ: Erlbaum

GoLD, P. E. (1984). Memory modulation: Roles of peripheral catecholamines. In L. Squire \& N. Butters (Eds.), The neuropsychology of memory (pp. 566-578). New York: Guilford Press.

Gold, P. E., Delanoy, R., \& Merrin, J. (1984). Modulation of longterm potentiation by peripherally administered amphetamine and epinephrine. Brain Research, 305, 103-107

GoLd, P. E., \& MCCARTY, R. (1981). Plasma catecholamines: Changes after footshock and seizure-producing frontal cortex stimulation. Behavioral \& Neural Biology, 31, 247-260.

Gold, P. E., McGaugh, J. L. (1975). A single-trace, two process view of memory storage processes. In D. Deutsch \& J. A. Deutsch (Eds.), Short-term memory (pp. 355-378). New York: Academic Press.

Gold, P. E., McGaugh, J. L. (1978). Endogenous modulators of memory storage processes. In L. Carenza, P. Pancherra, \& L. Zichella (Eds.), Clinical psychoneuroendocrinology in reproduction (pp. 25-46). New York: Academic Press.

Gold, P. E., McGaugh, J. L., Hankins, L. L., Rose, R. P., * VASQUez, B. J. (1981). Age-dependent changes in retention in rats. Experimental Aging Research, 8, 53-58.

Gold, P. E., MurPhy, J. M., C CoOley, S. (1982). Neuroendocrine modulation of memory during development. Behavioral \& Neural Biology, 35, 277-293.

Gold, P. E., \& STERNBerg, D. B. (1978). Retrograde amnesia produced by several treatments: Evidence for a common neurobiological mechanism. Science, 201, 367-369.

Gold, P. E., \& VAN BuskiRK, R. B. (1975). Facilitation of timedependent memory processes with posttrial epinephrine injections. Behavioral Biology, 13, 145-153.

Gold, P. E., \& VAN BuskiRK, R. B. (1976). Effects of posttrial hormone injections on memory processes. Hormones \& Behavior, 7 , 509-517.

Gold, P. E., VAN Buskirk, R. B. (1978a). Effects of alpha- and beta-adrenergic receptor antagonists on posttrial epinephrine modulation of memory: Relationship to posttraining brain norepinephrine concentrations. Behavioral Biology, 24, 168-184.

Gold, P. E., VAN BUSKIRK, R. B. (1978b). Posttraining brain norepinephrine concentrations: Correlation with retention performance of avoidance training and with peripheral epinephrine modulation of memory processing. Behavioral Biology, 23, 509-520.

Gold, P. E., Z ZoRNeTZER, S. F. (1983). The mnemon and its juices: Neuromodulation of memory processes. Behavioral \& Neural Biol$o g y, 38,151-189$.

MCCARTY, R. (1981). Aged rats: Diminished sympathetic-adrenal medul- 
lary response to acute stress. Behavioral \& Neural Biology, 33, 204-212.

MCCARTY, R., GolD, P. E. (1981). Plasma catecholamines: Effects of footshock level and hormonal modulators of memory storage. Hormones \& Behavior, 15, 168-182.

McGaugh, J. L. (1966). Time-dependent processes in memory storage. Science, 153, 1351-1358.

McGaugh, J. L. (1983). Hormonal influences on memory. Annual Review of Psychology, 34, 297-323.

McGaugh, J. L., Herz, M. J. (1972). Memory consolidation. San Francisco: Albion.

STernberG, D. B., \& Gold, P. E. (1980). Effects of alpha- and betaadrenergic receptor antagonists on retrograde amnesia produced by frontal cortex stimulation. Behavioral \& Neural Biology, 29, 289-302.

STERNBERG, D. B., \& GolD, P. E. (1981). Retrograde amnesia produced by electrical stimulation of the amygdala: Attenuation with adrenergic antagonists. Brain Research, 211, 59-65.

Sternberg, D. B., Martinez, J., Gold, P. E., \& McGaugh, J. L., (1985). Age-related memory deficits in aged rats and mice: Enhance- ment with peripheral injections of epinephrine. Behavioral \& Neural Biology, 44, 213-220.

Sternberg, D. B., McGaugh, J. L., \& Gold, P. E. (1983). Memory facilitation and impairment with supraseizure electrical brain stimulation: Attenuation with pretrial propranolol injections. Behavioral \& Neural Biology, 38, 261-268.

WeLSH, K. A., \& GolD, P. E. (1984). Attenuation of epileptogenesis: Proactive effect of a single epinephrine injection of amygdaloid kindling. Behavioral \& Neural Biology, 40, 179-185.

ZORNETZER, S. F. (1978). Neurotransmitter modulation and memory: A new neuropharmacological phrenology. In M. S. Lipton, A. DiMascio, \& K. F. Killam (Eds.), Psychopharmacology: A generation of progress (pp. 637-649). New York: Raven Press.

ZORNETZER, S. F., THOMPSON, R., \& Rogers, J. (1982). Rapid forgetting in aged rats. Behavioral \& Neural Biology, 36, 49-60.

(Manuscript received March 18, 1985; accepted for publication June 17, 1987.) 